\title{
Gambaran Skor Apgar pada Seksio Sesarea Antara Anestesi Spinal dan Anestesi Umum di RSUP Dr. Hasan Sadikin Periode Januari-Juni 2019
}

\author{
Muhammad Adjie Pratama, ${ }^{1}$ Iwan Fuadi, ${ }^{2}$ Dzulfikar D. L. Hakim ${ }^{3}$ \\ ${ }^{1}$ Fakultas Kedokteran, Universitas Padjadjaran Bandung, ${ }^{2}$ Departemen Anestesiologi dan Terapi \\ Intensif Fakultas Kedokteran Universitas Padjadjaran/Rumah Sakit Dr. Hasan Sadikin Bandung, \\ ${ }^{3}$ Departemen Ilmu Kesehatan Anak Fakultas Kedokteran Universitas Padjadjaran/ \\ Rumah Sakit Dr. Hasan Sadikin Bandung
}

\begin{abstract}
Abstrak
Angka kelahiran melalui tindakan seksio sesarea di Indonesia terus meningkat. Penggunaan anestesi saat dilakukan seksio sesarea dapat memengaruhi luaran bayi yang dilahirkan. Tujuan penelitian ini adalah melihat gambaran skor Apgar pada tindakan seksio sesarea antara anestesi spinal dan anestesi umum di RSUP Dr. Hasan Sadikin Bandung. Penelitian dilakukan dengan metode potong lintang deskriptif dengan menggunakan teknik total sampling. Data didapatkan dari rekam medis pasien yang menjalani tindakan seksio sesarea di RSUP Dr. Hasan Sadikin pada periode 1 Januari 2019 hingga 30 Juni 2019. Hasil penelitian didapatkan 368 bayi dan 345 ibu dengan sebaran 248 (73,4\%) ibu menggunakan anestesi spinal dan 90 (26,6\%) menggunakan anestesi umum. Skor Apgar 5 menit bayi dengan anestesi spinal pada kategori 0-3 sebanyak 3 (1,1\%), 4-7 sebanyak 18 (6,6\%), dan 8-10 sebanyak 251 (92,3\%). Skor Apgar 5 menit bayi dengan anestesi umum pada kategori 0-3 sebanyak 7 (7,3\%), 4-7 sebanyak $14(14,6 \%)$, dan 8-10 sebanyak 75 (78,1\%). Simpulan dari penelitian ini adalah persentase skor Apgar bayi yang lahir melalui seksio sesarea dengan ibu diberi anestesi spinal lebih tinggi dibandingkan dengan anestesi umum.
\end{abstract}

Kata kunci: Anestesi umum, anestesi spinal, seksio sesarea, skor Apgar

\section{Overview of Apgar Score in Cesarean Section between Spinal Anaesthesia and General Anaesthesia at RSUP Dr. Hasan Sadikin in January-June 2019}

\begin{abstract}
The birth rate through the cesarean section in Indonesia continues to increase. The use of anaesthesia during cesarean section can affect the outcome of the newborns. The purpose of this study was to look at the description of Apgar's score on the cesarean section between spinal anaesthesia and general anaesthesia at Dr. RSUP. Hasan Sadikin. The study was conducted with a cross-sectional descriptive method using a total sampling technique. Data were obtained from medical records of patients undergoing cesarean section at RSUP Dr. Hasan Sadikin in the period 1 January, 2019, to 30 June, 2019. The results showed 368 infants and 345 mothers with a distribution of $248(73.4 \%)$ mothers using spinal anaesthesia and 90 (26.6\%) using general anaesthesia. The 5-minute Apgar score of infants with spinal anaesthesia in the 0-3 category was $3(1.1 \%), 4-7$ was $18(6.6 \%)$, and 8-10 was 251 (92.3\%). Apgar scores for 5 minutes of infants with general anaesthesia in the $0-3$ category were $7(7.3 \%), 4-7$ were $14(14.6 \%)$, and $8-10$ were $75(78.1 \%)$. The conclusion of this study is the percentage of Apgar score of babies born through the cesarean section with mothers given spinal anaesthesia is higher compared with those given general anaesthesia.
\end{abstract}

Key words: Apgar score, cesarean section, general anaesthesia, spinal anaesthesia

Korespondensi: dr. Muhammad Adjie Pratama, Fakultas Kedokteran, Universitas Padjadjaran, Bandung, Jl. Prof. Eyckman No. 38 Bandung 40161, Tlpn 022-2038114,Email muhammad16099@mail.unpad.ac.id 


\section{Pendahuluan}

Angka kematian ibu di Jawa Barat pada tahun 2015 sebanyak 87,54 per 100.000 kelahiran. Angka kematian ibu di Jawa Barat lebih rendah dari target World Health Organization (WHO), yaitu 102 per 100.000 kelahiran. ${ }^{1}$ Seksio sesarea merupakan tindakan yang membantu untuk menurunkan angka kematian ibu dikarenakan dapat menyelamatkan nyawa untuk ibu dan bayi ketika terdapat komplikasi pada kehamilan. ${ }^{2}$ Angka kelahiran dengan seksio sesarea meningkat di seluruh dunia baik di negara maju maupun berkembang. ${ }^{3}$ Pada tahun 2015 kelahiran melalui tindakan seksio sesarea lebih dari $20 \%$ dari total kelahiran di Asia. Negara berkembang khususnya di Asia Tenggara memiliki angka kelahiran dengan seksio sesarea lebih tinggi dari rata-rata di Asia. Kelahiran melalui seksio sesarea di Indonesia sebesar 29,6\% dari total kelahiran yang ada di Indonesia. ${ }^{4}$

Penggunaan anestesi diperlukan untuk menghilangkan rasa nyeri saat dilakukan operasi dan mengurangi rasa nyeri setelah operasi. Jenis anestesi yang dapat digunakan untuk tindakan seksio sesarea adalah anestesi umum, anestesi spinal, dan anestesi epidural. Anestesi yang sering digunakan untuk tindakan seksio sesarea adalah anestesi spinal dan anestesi umum. ${ }^{5}$

Angka kematian bayi di RSUP Dr. Hasan Sadikin Bandung pada tahun 2016 sebanyak 81,4 per 1.000 kelahiran dan salah satu penyebab kematian paling sering adalah asfiksia neonatus. ${ }^{1}$ Kondisi bayi sesaat setelah lahir dinilai dengan skor Apgar untuk menentukan keadaan umum bayi sesaat setelah dilahirkan. ${ }^{6}$ Penilaian skor Apgar digunakan untuk penentuan awal apakah terdapat asifiksia pada bayi atau tidak. ${ }^{7}$ Berdasar atas penelitian lainnya diketahui penggunaan anestesi spinal untuk tindakan seksio sesarea menyebabkan hipotensi pada ibu sedangkan penggunaan anestesi umum menyebabkan skor Apgar 1 menit dan 5 menit lebih rendah dibanding dengan pasien yang menggunakan anestesi spinal. $^{8}$ Penelitian lain yang dilakukan di Kolumbia menemukan penggunaan anestesi spinal dan anestesi umum menunjukan skor Apgar 1 menit dan 5 menit tidak berbeda antara kedua jenis anestesi tersebut. ${ }^{9}$

Tujuan penelitian ini adalah melihat gambaran luaran bayi yang dinilai melalui skor Apgar bayi saat dilahirkan melalui tindakan seksio sesarea antara ibu yang diberi anestesi spinal dan ibu yang diberi anestesi umum di Rumah Sakit Umum Pusat Dr. Hasan Sadikin Bandung pada periode 1 Januari 2019 hingga 30 Juni 2019.

\section{Subjek dan Metode}

Desain studi pada penelitian ini adalah potong lintang secara deskriptif. Penelitian ini dilakukan di Rumah Sakit Dr. Hasan Sadikin Bandung menggunakan data rekam medis pasien yang menjalani tindakan seksio sesarea dari Januari hingga Juni tahun 2019. Subjek penelitian ini adalah pasien yang menjalani seksio sesarea dengan kriteria inklusi menggunakan anestesi spinal atau anestesi umum dan kriteria eksklusi bayi yang dilahirkan meninggal dalam kandungan dan data rekam medis tidak lengkap.

Metode pengumpulan data adalah total sampling dengan mengambil seluruh data rekam medis tindakan seksio sesarea yang dilaksanakan pada 1 Januari 2019 hingga 30 Juni 2019 di RSUP Dr. Hasan Sadikin Bandung. Sebelum melakukan pengambilan data sudah mendapatkan persetujuan dari Komite Etik Penelitian Fakultas Kedokteran Universitas Padjadjaran dengan nomor 811/ UN6.KEP/EC/2019 dan surat izin penelitian dari bagian Pendidikan dan Penelitian RSUP Dr. Hasan Sadikin Bandung untuk melakukan pengambilan data di instalasi rekam medis.

\section{Hasil}

Penelitian ini dilakukan di Rumah Sakit Dr. Hasan Sadikin Bandung menggunakan data rekam medis pasien yang menjalani tindakan seksio sesarea pada periode Januari hingga Juni 2019. Terdapat 345 rekam medis yang didapatkan dalam penelitian ini namun yang 
Table 1 Karakteristik Umum Pasien

\begin{tabular}{lccc}
\hline \multicolumn{1}{c}{ Variabel } & $\begin{array}{c}\text { Anestesi Spinal } \\
(\mathbf{n = 2 4 8})\end{array}$ & $\begin{array}{c}\text { Anestesi Umum } \\
(\mathbf{n = 9 0})\end{array}$ & $\begin{array}{c}\text { Total } \\
(\mathbf{n = 3 3 8})\end{array}$ \\
\hline $\begin{array}{l}\text { Usia Ibu (tahun) } \\
\text { <20 }\end{array}$ & $13(5,2 \%)$ & $9(10 \%)$ & $22(6,5 \%)$ \\
$20-35$ & $164(66,1 \%)$ & $54(60 \%)$ & $218(64,5 \%)$ \\
$>35$ & $71(28,6 \%)$ & $27(30 \%)$ & $100(29 \%)$ \\
Usia gestasi (minggu) & & & \\
$\quad$ Preterm (<34) & $73(29,4 \%)$ & $34(37,8 \%)$ & $107(31,7 \%)$ \\
Late preterm (34-36) & $41(16,5 \%)$ & $12(13,3 \%)$ & $53(15,7 \%)$ \\
Term (37-42) & $134(54 \%)$ & $44(48,9 \%)$ & $178(52,7 \%)$ \\
Jumlah tindakan & & & \\
$\quad$ Indikasi tunggal & $160(64,5 \%)$ & $55(61,1 \%)$ & $215(63,6 \%)$ \\
Indikasi multipel & $88(35,5 \%)$ & $35(38,9 \%)$ & $123(36,4 \%)$ \\
\hline
\end{tabular}

memenuhi kriteria sebanyak 338 rekam medis. Terdapat sebanyak 26 pasien yang melahirkan bayi kembar dua dan 2 pasien pasien melahirkan bayi kembar tiga sehingga terdapat 368 bayi yang digunakan dalam penelitian ini.

Tindakan seskio sesarea dengan ibu diberi anestesi spinal sebanyak $248(73,4 \%)$ pasien dan tindakan seksio sesarea dengan ibu diberi anestesi umum sebanyak 90 (26,6\%) pasien. Usia ibu paling banyak yang menjalani tindakan seksio sesarea pada kelompok 20-34 tahun sebanyak 218 pasien dengan persentase lebih banyak pada pasien diberi anestesi spinal $66,1 \%$. Usia gestesi pasien yang menjalani tindakan seksio sesarea paling banyak adalah term (37-42 minggu) sebanyak 178 pasien dengan persentase lebih besar pada ibu yang diberi anestesi spinal 54\%.

Indikasi tindakan seksio sesarea dengan indikasi tunggal merupakan yang paling banyak dengan 215 pasien dan persentase lebih tinggi pada pasien dengan anestesi spinal sebanyak $64,5 \%$ sedangkan untuk indikasi seskio sesarea yang lebih dari satu sebanyak 123 pasien dengan persentase lebih tinggi pada pasien dengan anestesi umum sebanyak 38,9\% (Tabel 1).

Pada bayi yang lahir dengan ibu diberi anestesi spinal paling banyak pada kategori low birthweight sebanyak 123 bayi dan paling sedikit pada kategori makrosomia sebanyak 3 bayi. Untuk bayi yang lahir dari ibu diberi anestesi umum paling banyak pada kategori normal birthweight sebanyak 40 bayi dan pada kategori makrosomia tidak terdapat bayi lahir dari ibu diberi anestesi umum (Tabel 2).

Pada skor Apgar 1 menit untuk bayi dengan ibu diberi anestesi spinal paling banyak pada kelompok skor Apgar 4-7 yaitu 227 bayi $(83,5 \%)$ dan paling sedikit pada kelompok skor Apgar 0-3 sebanyak 7 (2,6\%) bayi. Pada

Tabel 2 Karakteristik Berat Lahir Bayi

\begin{tabular}{lccc}
\hline Berat Lahir Bayi & $\begin{array}{c}\text { Anestesi Spinal } \\
(\mathbf{n = 2 7 2 )}\end{array}$ & $\begin{array}{c}\text { Anestesi Umum } \\
(\mathbf{n = 9 6 )}\end{array}$ & $\begin{array}{c}\text { Total } \\
(\mathbf{n = 3 6 8 )}\end{array}$ \\
\hline Extremely low birthweight $(<1.000 \mathrm{~g})$ & $4(1,5 \%)$ & $3(3,1 \%)$ & $7(1,9 \%)$ \\
Very low birthtweight (1.000 g-1.499 g) & $21(7,7 \%)$ & $17(17,7 \%)$ & $38(10,3 \%)$ \\
Low birthweight (1.500 g-2.499 g) & $123(45,2 \%)$ & $36(37,5 \%)$ & $159(43,2 \%)$ \\
Normal birthweight (2.500 g-3.999 g) & $121(44,5 \%)$ & $40(41,7 \%)$ & $162(43,2 \%)$ \\
Makrosomia (4.000 g) & $3(1,1 \%)$ & $0(0 \%)$ & $3(0,8 \%)$ \\
\hline
\end{tabular}


Tabel 3 Gambaran Skor Apgar pada Seksio Sesarea

\begin{tabular}{|c|c|c|c|c|c|c|c|c|}
\hline \multirow{4}{*}{ Skor Apgar ${ }^{10}$} & \multicolumn{4}{|c|}{ Menit ke-1 } & \multicolumn{4}{|c|}{ Menit ke-5 } \\
\hline & \multicolumn{8}{|c|}{ Jenis Anestesi } \\
\hline & \multicolumn{2}{|c|}{$\begin{array}{c}\text { Spinal } \\
(n=272)\end{array}$} & \multicolumn{2}{|c|}{$\begin{array}{l}\text { Umum } \\
(n=96)\end{array}$} & \multicolumn{2}{|c|}{$\begin{array}{c}\text { Spinal } \\
(n=272)\end{array}$} & \multicolumn{2}{|c|}{$\begin{array}{l}\text { Umum } \\
(n=96)\end{array}$} \\
\hline & $\mathbf{n}$ & $\%$ & $\mathbf{n}$ & $\%$ & $\mathbf{n}$ & $\%$ & $\mathbf{n}$ & $\%$ \\
\hline 0-3 (Asfiksia berat) & 7 & 2,6 & 13 & 13,5 & 3 & 1,1 & 7 & 7,3 \\
\hline 4-7 (Asfiksia ringan sedang) & 227 & 83,5 & 79 & 82,3 & 18 & 6,6 & 14 & 14,6 \\
\hline 8-10 (Tidak asfiksia) & 38 & 14 & 4 & 4,2 & 251 & 92,3 & 75 & 78,1 \\
\hline
\end{tabular}

bayi yang lahir dari ibu diberi anestesi umum paling banyak berada pada kelompok skor Apgar 4-7 sebanyak 79 (82,5\%) bayi dan paling sedikit pada kelompok skor Apgar 8-10 sebanyak $4(4,2 \%)$ bayi.

Untuk skor Apgar 5 menit pada bayi yang lahir dari ibu yang diberi anestesi spinal paling banyak pada kelompok skor Apgar 8-10 sebanyak $251 \quad(92,3 \%)$ dan paling sedikit berada pada kelompok skor Apgar 0-3 sebanyak $3(1,1 \%)$. Pada bayi yang lahir dengan ibu diberi anestesi umum paling

Tabel 4 Indikasi Tindakan Seksio Sesarea

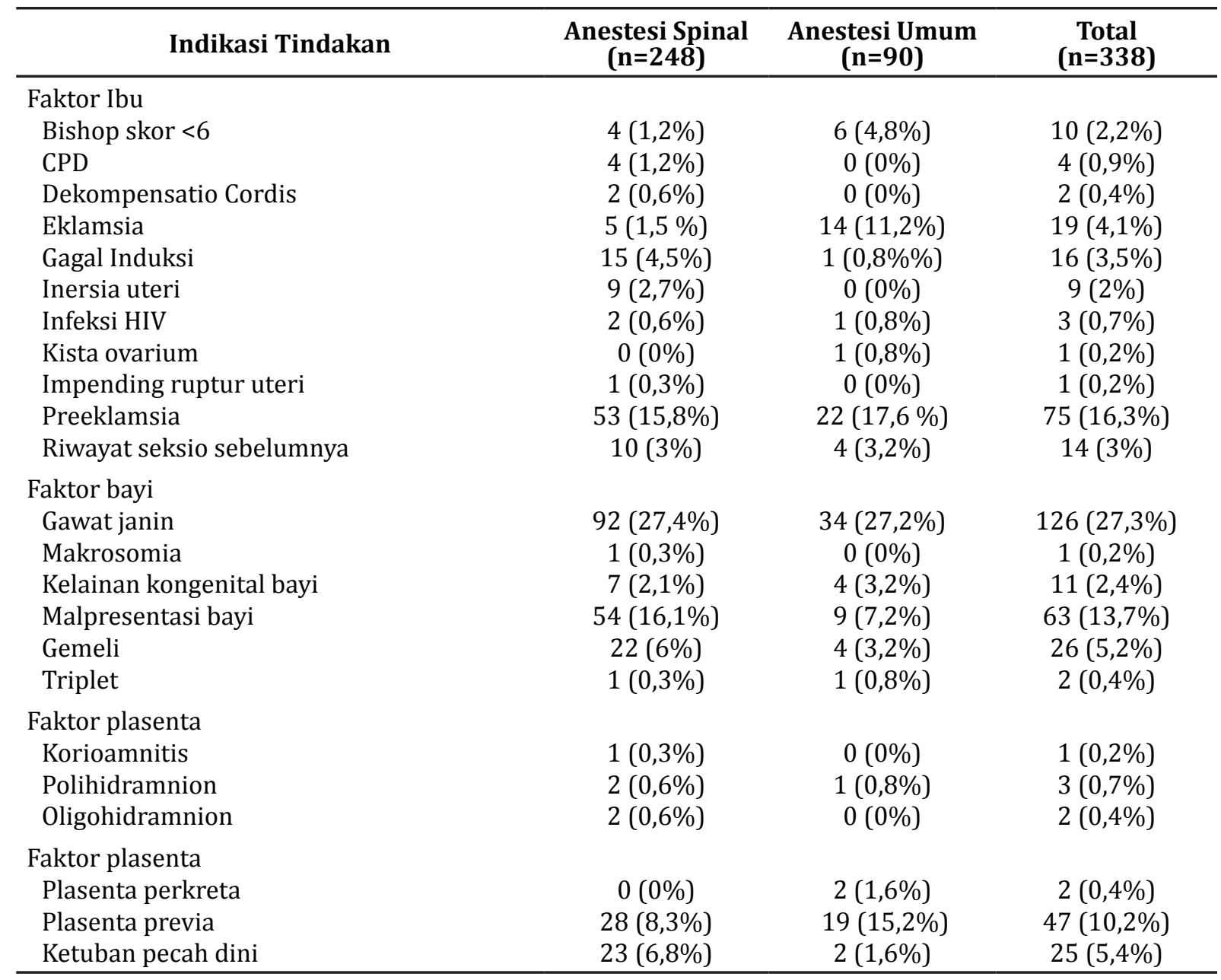


banyak terdapat pada kelompok skor Apgar $8-10$, yaitu sebanyak $75(78,1 \%)$ dan paling sedikit pada kelompok skor Apgar 0-3, yaitu sebanyak 7 (7,3\%; Tabel 3)

Indikasi tindakan seksio sesarea paling banyak dari faktor ibu adalah preeklamsia sebanyak 75 pasien dengan persentase lebih besar pada pasien dengan anestesi umum sebesar $17,6 \%$. Indikasi tindakan seksio sesarea paling banyak dari faktor bayi, yaitu gawat janin sebanyak 126 pasien dengan persentase lebih besar pada pasien dengan anestesi spinal sebesar 27,4\%. Indikasi seksio sesarea paling banyak dari faktor plasenta adalah plasenta previa sebanyak 47 pasien dengan persentase lebih besar pada pasien dengan anestesi umum sebesar 15,2\%. Terdapat ibu yang melahirkan bayi lebih dari satu dan paling banyak terdapat pada kelompok anestesi spinal sebanyak 22 (6\%) bayi kembar 2 dan untuk bayi kembar tiga pada kelompok anestesi spinal dan anestesi umum masing-masing satu pasien dengan bayi kembar tiga (Tabel 4).

\section{Pembahasan}

Hasil penelitian ini didapatkan dari 338 pasien yang menjalani tindakan seksio sesarea di RSUP Dr. Hasan Sadikin Bandung pada periode Januari hingga Juni 2019 dengan pesebaran $248(73,6 \%)$ pasien menggunakan anestesi spinal dan $90(26,6 \%)$ pasien menggunakan anestesi umum. Berdasar atas penelitian lainnya penggunaan anestesi spinal lebih banyak digunakan untuk tindakan seksio sesarea dibanding dengan anestesi umum sesuai dengan data penelitian yang dilakukan di RSUP Dr. Hasan Sadikin Bandung didapatkan data bahwa $73,6 \%$ tindakan seksio sesarea menggunakan anestesi spinal. ${ }^{11}$ Penggunaan anestesi umum dapat menyebabkan terjadinya aspirasi saat melakukan tindakan intubasi, mual, muntah, dan nyeri tenggorokan pasca operasi. Tata laksana jalan napas tidak diperlukan pada penggunaan anestesi spinal sehingga tidak ada kemungkinan untuk terjadi gagal intubasi. ${ }^{5}$ Penggunaan anestesi spinal menjadi pilihan utama pada tindakan seksio sesarea dikarenakan lebih aman dan minim komplikasi dibanding dengan pengunaan anestesi umum. ${ }^{12}$

Pada penelitian ini didapatkan skor Apgar 1 menit bayi dengan ibu diberi anestesi umum secara persentase lebih banyak pada kategori skor Apgar 0-3 dan lebih sedikit pada kategori 8-10 dibanding dengan bayi yang lahir dengan ibu diberi anestesi spinal sehingga secara keseluruhan skor Apgar 1 menit bayi dengan ibu diberi anestesi umum lebih banyak yang rendah. Hal ini sesuai dengan penelitian yang dilakukan di Mesir diketahui bahwa skor Apgar 1 menit bayi dari ibu yang lahir dengan anestesi spinal lebih tinggi dibanding dengan bayi yang lahir dari ibu diberi anestesi umum. ${ }^{12}$ Penelitian lain menyebutkan bahwa skor Apgar 1 menit yang rendah pada bayi tidak hanya dipengaruhi oleh jenis anestesi tetapi dipengaruhi oleh banyak faktor misalnya indikasi seksio sesarea. ${ }^{11}$

Hasil penelitian yang dilakukan di RSUP Dr. Hasan Sadikin Bandung menunjukan bahwa skor Apgar 5 menit bayi dengan ibu diberi anestesi umum secara persentase lebih banyak pada kategori skor Apgar 0-3 dan skor Apgar 4-7 sedangkan pada kategori skor Apgar 8-10 lebih banyak pada bayi yang lahir dengan ibu diberi anestesi spinal sehingga terlihat bahwa skor Apgar 5 menit bayi dengan ibu diberi anestesi umum lebih banyak yang rendah. Hal ini sejalan dengan penelitian sebelumnya yang menyatakan bahwa skor Apgar 5 menit bayi dengan anestesi spinal lebih tinggi dibandingkan dengan bayi yang lahir dengan anestesi umum. ${ }^{12}$

Skor Apgar 5 menit dapat digunakan untuk penilaian awal asfiksia nenonatus. Kelompok skor Apgar 0-3 dapat disebut bayi tersebut mengalami asfiksia berat. ${ }^{10}$ Pada penelitian ini menemukan bahwa lebih banyak bayi yang mungkin mengalami asfiksia pada bayi yang lahir dengan ibu diberi anestesi umum. Penggunaan anestesi umum pada tindakan seksio sesarea dapat menyebabkan obat golongan opioid seperti remifentanil yang dimasukan secara intravena pada ibu tersebar secara sistemik dan masuk ke aliran darah bayi melalui plasenta sehingga menyebabkan 
ganguan pernapasan pada bayi saat dilahirkan. Obat pelumpuh otot yang diberikan untuk intubasi seperti rokuronium dan suksinilkolin bersifat polar sehingga mudah terionisasi yang menyebabkan pengaruh pada bayi sangat minimal.

Penggunaan obat anestesi secara inhalasi seperti sevoflurane juga dapat menyebabkan ganguan pernafasan pada bayi sehingga bayi harus dilahirkan 15 menit setelah pemberian induksi anestesi untuk meminimalisir efek pada bayi. Resusitasi neonatus dan skor Apgar yang rendahlebih banyak terjadi pada bayi lahir dari ibu dengan anestesi umum dibandingkan dengan ibu yang diberi anestesi spinal. Obat yang digunakan pada anestesi spinal adalah obat anestesi lokal seperti lidokain dan bupivakain dengan obat opioid hanya sebagai adjuvan. Pada ibu yang diberi anestesi spinal, obat anestesi dimasukan langsung ke saraf tulang belakang sehingga obat tidak tersebar secara sistemik ke aliran darah ibu. ${ }^{5}$ Penggunaan opioid pada anestesi umum dimasukan secara sistemik melalui peredaran darah ibu sedangkan pada anestesi spinal dimasukan melalui saraf tulang belakang dan hanya dalam jumlah sedikit sebagai adjuvan. Hal ini kemungkinan dapat menyebabkan skor Apgar bayi yang lahir dari ibu diberi anestesi spinal lebih tinggi dibandingkan dengan bayi yang lahir dari ibu diberi anestesi umum.

Bayi yang lahir di RSUP Dr. Hasan Sadikin pada kelompok usia kehamilan kurang dari 34 minggu (preterm) sebanyak 107 pasien dengan persentase lebih tinggi pada pasien dengan anestesi umum yaitu 37,8\% dibandingkan dengan anestesi spinal 29,4\%. Usia kehamilan kurang bulan akan berpengaruh terhadap luaran bayi saat dilahirkan. Berdasarkan penelitian lain diketahui bayi yang lahir kurang bulan memiliki skor Apgar 5 menit lebih rendah dan risiko 6 kali lebih besar untuk memiliki skor Apgar 5 menit kurang dari 7. Skor Apgar yang rendah tersebut kemungkinan dipengaruhi oleh sistem pernapasan yang belum matang dan regulasi aliran darah otak yang belum sempurna sehingga sistem saraf tergangu. ${ }^{13}$ Pasien yang diberi anestesi umum memiliki persentase lebih tinggi pada kelompok usia kehamilan dibawah 34 minggu (preterm) yang mungkin berpengaruh terhadap skor Apgar bayi lebih rendah pada bayi yang dilahirkan dengan ibu diberi anestesi umum.

Bayi yang lahir di RSUP Dr. Hasan Sadikin dengan berat dibawah $2500 \mathrm{~g}$ secara persentase lebih banyak pada ibu yang diberi anestesi umum. Berat bayi kurang dari $2500 \mathrm{~g}$ saat lahir menurut penelitian lain menyebabkan skor Apgar 1 dan 5 menit lebih rendah. Komplikasi kehamilan lebih banyak terjadi pada ibu dengan bayi lahir berat rendah seperti denyut jantung janin tidak normal, usia kehamilan kurang bulan, dan jumlah air ketuban tidak normal. ${ }^{14}$ Hal ini kemungkinan dapat menyebabkan skor Apgar pada bayi yang lahir dari ibu yang diberi anestesi umum lebih rendah.

Indikasi seksio sesarea dari faktor ibu yang paling banyak adalah preeklamsia sebanyak 75 pasien dengan persentase lebih besar pada anestesi umum $(17,6 \%)$ dibandingkan dengan anestesi spinal (15,85\%). Berdasarkan penelitian lain menyatakan bahwa pasien dengan preeklamsia akan melahirkan bayi dengan skor Apgar 1 menit yang lebih rendah. Rendahnya skor Apgar pada bayi dengan ibu preeklamsia mungkin disebabkan oleh lebih banyak bayi lahir pada usia kehamilan kurang dari 34 minggu dari ibu preeklamsia. Preeklamsia menyebabkan terganggunya aliran darah uteroplasenta yang dapat menyebabkan tergangunya pemberian oksigen kepada bayi. ${ }^{15}$ Persentase pasien yang menjalanin tindakan seksio sesarea dengan menggunakan anestesi umum lebih banyak dengan indikasi preeklamsia yang mungkin berpengaruh kepada rendahnya skor Apgar bayi yang lahir dengan ibu diberi anestesi umum.

Indikasi seksio sesarea dari faktor plasenta yang paling banyak adalah plasenta previa sebanyak 47 pasien dengan persentase lebih besar pada pasien dengan anestesi umum yaitu $15,2 \%$ dibandingkan dengan anestesi spinal hanya $8,3 \%$. Menurut penelitian yang dilakukan di Jepang diketahui bahwa pasien dengan plasenta previa memiliki risiko lebih 
tinggi untuk melahirkan bayi prematur dan bayi yang lahir memiliki skor Apgar lebih rendah. ${ }^{16}$ Penelitian di Taiwan menemukan bahwa pasien dengan plasenta previa melahirkan bayi dengan skor Apgar 1 menit dan 5 menit kurang dari 7 lebih banyak dibandingkan bayi yang lahir dengan ibu tidak dengan plasenta previa. Plasenta previa juga dikaitkan sebagai salah satu penyebab preeklamsia dikarenakan plasenta menempel pada bagian bawah rahim yang memiliki pembuluh arteri spiral yang lebih sedikit dibandingnya pada bagian fundus rahim. ${ }^{17}$ Persentase plasenta previa pada pasien yang diberi anestesi umum lebih tinggi dibandingkan dengan pasien yang diberi anestesi spinal hal ini mungkin menyebabkan skor Apgar pada bayi dari pasien yang diberi anestesi umum memiliki skor Apgar lebih rendah.

Keterbatasan pada penelitian ini adalah jumlah data yang tidak sama antara kelompok pasien yang menggunakan anestesi spinal dan anestesi umum sehingga data dari kedua kelompok tersebut hanya dapat dibandingkan secara persentase. Penilaian skor Apgar dilakukan oleh orang yang berbeda kemungkinan juga dapat menyebabkan penilaian yang tidak sama setiap orangnya dikarenakan diukur secara kualitatif oleh orang.

\section{Simpulan}

Berdasarkan penelitian yang dilakukan di RSUP Dr. Hasan Sadikin pada periode Januari hingga Juni 2019 ditemukan bahwa skor Apgar bayi yang dilahirkan dengan ibu diberi anestesi spinal lebih tinggi dibandingkan dengan bayi yang lahir dari ibu yang diberi anestesi umum. Bayi dengan asfiksia secara persentase lebih banyak pada bayi lahir dari ibu diberi anestesi umum. Menurut data yang didapat ada beberapa faktor yang mungkin menyebabkan skor Apgar bayi dari ibu yang diberi anestesi umum lebih rendah yaitu usia kehamilan prematur, preeklamsia, plasenta previa dan bayi berat lahir rendah karena secara persentase indikasi tersebut lebih banyak pada pasien yang diberi anestesi umum. Kemungkinan lebih rendahnya skor Apgar bayi yang lahir dengan ibu diberi anestesi umum bukan hanya disebabkan oleh jenis anestesi namun dipengaruhi oleh faktorfaktor lainnya.

\section{Daftar Pustaka}

1. Djembarsari A, Hidajat N, Supriatna YA, Kadarsah R. Laporan akuntabilitas kinerja RSUP Dr. Hasan Sadikin Bandung, Tahun 2016. Bandung; 2016.

2. Boerma T, Ronsmans C, Melesse DY, Barros AJD, Barros FC, Juan L, dkk. Global epidemiology of use of and disparities in caesarean sections. Lancet. 2018;392(10155):1341-8.

3. Department of Reproductive Health and Research World. WHO statement on caesarean section rates. WHO. World Health Organization; 2019.

4. Festin MR, Laopaiboon M, Pattanittum P, Ewens MR, Henderson-Smart DJ, Crowther CA, dkk. Caesarean section in four South East Asian countries: reasons for, rates, associated care practices and health outcomes. BMC Pregnancy Childbirth. 2009;9:17.

5. Palmer CM, D’Angelo R, Paech MJ. Obstetric anesthesia. Edisi ke-1. Obstetric anesthesia. New York: Oxford University Press; 2011.

6. Williams JW, Cunningham FG, Leveno KJ, Bloom SL, Spong CY, Dashe JS. Williams Obstetrics, 25. Edisi ke-25. Williams Obstetrics. New York: N.Y.: McGraw Hill Medical; 2018.

7. Ugwu GIM, Abedi HO, Ugwu EN. Incidence of birth asphyxia as seen in central hospital and GN children's clinic both in Warri Niger Delta of Nigeria: an eight year retrospective review. Glob J Health Sci. 2012;4(5):140-6.

8. Flora L, Redjeki IS, Wargahadibrata AH. Perbandingan efek anestesi spinal dengan anestesi umum terhadap kejadian hipotensi dan nilai Apgar bayi pada seksio sesarea. JAP. 2014;2(2):105-16.

9. Páez L JJ, Navarro V JR. Anestesia regional 
versus general para parto por cesárea. Vol. 40, Revista Colombiana de Anestesiología. Kolumbia: scieloco; 2012. hlm. 203-6.

10. Gomella TL, Cunningham MD, Eyal FG, Tuttle D. Neonatology: management, procedures, on-call problems, diseases, and drugs. Edisi ke-7. Neonatology. New York: Lange; 2013.

11. Obi VO, Umeora OUJ. Anesthesia for emergency cesarean section: A comparison of spinal versus general anesthesia on maternal and neonatal outcomes. African J Med Heal Sci. 2018;17:31-4.

12. Madkour N, Ibrahim S, Ezz G. General versus spinal anesthesia during elective cesarean section in term low-risk pregnancy as regards maternal and neonatal outcomes: a prospective, controlled clinical trial. Res Opin Anesth Intens Care. 2019;6:119-24.

13. Lee HC, Subeh M, Gould JB. Low Apgar score and mortality in extremely preterm neonates born in the United States. Acta
Paediatr. 2010;99(12):1785-9.

14. Coutinho PR, Cecatti JG, Surita FG, Costa ML, Morais SS. Perinatal outcomes associated with low birth weight in a historical cohort. Reprod Health. 2011;8(1):18.

15. Susilo SA, Pratiwi KN, Fattah ANA, Irwinda R, Wibowo N. Determinants of low APGAR score among preeclamptic deliveries in Cipto Mangunkusumo Hospital: a retrospective cohort study in 2014. Med J Indones. 2015;24:183-9.

16. Sekiguchi A, Nakai A, Kawabata I, Hayashi M, Takeshita T. Type and location of placenta previa affect preterm delivery risk related to antepartum hemorrhage. Int J Med Sci. 2013;10(12):1683-8.

17. Baumfeld Y, Herskovitz R, Niv ZB, Mastrolia SA, Weintraub AY. Placenta associated pregnancy complications in pregnancies complicated with placenta previa. Taiwan J Obstet Gynecol. 2017;56(3):331-5. 